\title{
Highway Disaster Alignment Decision-making Model Under the Fragile Environment Condition in Mountain Area
}

\author{
Gao Chuandong ${ }^{1,2, *}$, Wu Guoxiong ${ }^{1,2}$ and Liu Guodong ${ }^{1,2}$ \\ ${ }^{I}$ National and Local Joint Engineering Laboratory of Traffic Civil Engineering Materials, Chongqing Jiaotong \\ University, Chongqing 400074, China \\ ${ }^{2}$ Institute of Civil \& Architecture, Chongqing, Jiaotong University, Chongqing 400074, China
}

\begin{abstract}
Highway disaster alignment is a complex multi-object decision-making problem especially under frail environment conditions such as in mountainous areas. In addition, these objects do not have public characteristics. This paper established the multi-object functional decision making model from the topographic, geologic environmental aspect that may grow and become the cause of all kinds of highway disasters. Using the multi-object decision making theory, this model considered the multi-object forthe highway alignment from the qualitative and quantitative aspect, which has an important academic significance and applied value. In the end of this paper, an example of the analysis is given which indicated the model and its effectivness.
\end{abstract}

Keywords: Decision-making model, frail environment, highway, disaster alignment, mountain area, multi-object.

\section{INTRODUCTION}

Construction of highway projects in mountainous areas where the environmental conditions are fragile usually poses a great impact on the fragile environment and can contribute to the development and occurrence of various highway disasters. This is one of the reasons for the predominant disaster and environmental problems with highway projects in mountainous areas. People nowadays are more aware of the environmental problems and their perceptions are also changing. This paper examines the disaster-based route selection and establishes a multi-object decision-making model based on the multi-object decision theory, on the basis of which the construction of highway projects in mountainous areas may give rise to the development and occurrence of highways by taking terrain-based route selection [1], geology-based route selection [2-4], and environment-based route selection [5-7] into consideration. This reflects the specification of the application of disasterbased route selection concept in the highway project construction scheme and decision making in the fragile environmental condition of the mountainous areas.

Currently, many studies are being conducted on highway disasters. For example, Ma Baocheng [8] et al. proposed predisaster identification criteria for highway collapse and landslide, respectively. Song Yanhui [9] et al. discussed the geological disaster evaluation model for highways in mountainous areas. Moreover, a great number of studies are

*Address correspondence to this author at the Institute of Civil \& Architecture, Chongqing Jiaotong University, Chongqing 400074, China; E-mail: 274283523@qq.com also being conducted on geological disaster risk evaluation [10-12]. The application of GIS technology $[13,14]$ provides a new technical research means for the risk assessment of highway geological hazards in the mountain areas. With regard to highway route selection. Sun Qingzhen [15] established a route optimization model for highways in mountainous areas based on the multi-object decision. Ye Liya [16] et al. conducted highway route optimization technology study on the basis of the geological disaster risk evaluation. This paper established a highway disaster-based route selection decision model according to the sensitive environmental condition in the mountainous areas, using the multi-object decision theory [17], in order to reduce or avoid the risk of highway disasters from the source of highway construction.

\section{FEATURES OF HIGHWAY DISASTER-BASED ROUTE SELECTION IN THE FRAGILE ENVIRON- MENTAL CONDITIONS OF MOUNTAINOUS AREAS}

Highway disaster-based route selection in the sensitive environmental condition of mountainous areas is a complicated systematical work and is also the key element that reflects the design characteristics and level of a project. Meanwhile, it is also a critical factor for guaranteeing safe operation for the routes and reduction of building cost. Taking all these factors into consideration helps guarantee the safety, economy, reasonability and the environmental performance of the highways, especially for route scheme selection in mountainous areas where the terrain condition, geological condition and environmental conditions are complicated. 
The fragile environmental conditions of the mountainous areas usually include rivers and mountains. The bank slopes are usually steep and the water flow is usually rapid. The steep mountains make roadbed filing and excavation very difficult, and once there is any uneven filling, spoil treatment becomes very difficult. On the other hand, the bridge and tunnel construction cost is very high. Though after accumulating a very rich experience in route selection regarding mountainous areas, such as mountain-crossing setting out, the work load is really high, which may cause stiff route developments, poor linearity and unsatisfactory operating conditions and other adverse effects. Meanwhile, the complicated and steep terrain also contributes greatly to the development and occurrence of various highway disasters.

The geology under crucial environmental condition in mountainous areas usually includes fault and its secondary fractured clamping zone or influence zone $[2,4]$. Rock mass fracture, karst, landslide, debris flow, collapse, crag, separation, rock-fall, talus and other undesired geology could easily be observed in those areas. Complicated geology provides very good material conditions for the development and occurrence of various highway disasters and highway secondary disasters.

The environmental conditions in the mountainous areas are usually extremely sensitive, such as sparse vegetation environment, complicated hydrological environment and severe weather environment. Any improper treatment in the highway project construction in the mountainous areas can be very hard to repair, and poses significant impact on the environment in the mountainous areas causing great troubles in the subsequent maintenance and operation.

\section{SELECTION OF HIGHWAY DISASTER-BASED ROUTE SELECTION DECISION OBJECTIVE UNDER THE FRAGILE ENVIRONMENTAL CONDITION OF MOUNTAINOUS AREAS}

Proper selection of highway disaster-based route selection decision object is the foundation for building a decision making model, and whether the decision making selection and quantification are reasonable, pose a direct impact on establishing decision making model $[3,5]$. Therefore, in the construction of highways, disaster-based route selection decision making model under sensitive environmental condition of the mountainous areas, reasonable selection of decision making object is quite critical. The factors impacting the highway disaster-based route selection with respect to terrain conditions, geological conditions and environmental conditions should be emphasized. The theoretical method for principal component analysis and clustering analysis is based on the principles of relative uniformity. Dominance and comprehensiveness should be considered to analyze and classify the highway route selection decision making indexes, following which the main representative objects should be taken as the decision making object to be studied according to the terrain, geology and environment [18].
Terrain object: The magnitude of terrain height is one of the critical factors impacting the route linearity and highway project quantity, and is also one of the main factors to be considered for route selection of highways in mountainous areas where the environment is sensitive. If the consideration is not comprehensive, there is high embankment and low cutting, thus increasing the damage in highway project construction due to the environment. If the bridges or tunnels are used instead, the project building cost is drastically increased. In addition, the steep terrain could also contribute to the occurrence and development of various highway disasters, such as landslide, collapse and debris flow and other common disasters. Therefore, the use of terrain as one of the decision making indexes has great significance for the safety and economy of highway construction projects. A slope map was generated, using the space analysis function of GIS to analyze the original 3D terrain data.In addition, on the basis of this generated slope map, the terrain elevation of different changes in the information of various grids was generated based on the information indexes reflecting the degree of impact of terrain objects on the linearity, safety and project quality of the route, and also on the information index reflecting the degree of impact of terrain objects on the occurrence of highway disasters. Based on the above analysis, the terrain information could be divided into flat terrain (with gradient below $30^{\circ}$ ), comparatively steep terrain (with gradient between $30^{\circ} \sim 45^{\circ}$ ) and steep terrain (with gradient above $\left.45^{\circ}\right)$.

Geology objective: The formation of lithology is one of the main factors to be considered for geology-based route selection of highways in sensitive environmental condition in mountainous areas. This is because the loose and fractured rock mass is regarded as the material condition for the occurence of various highway disasters. The development and occurrence of highway disasters in mountainous areas are closely related to the rate of decay of rock and lithology. Considering the lithology of rocks that differs when the locations and the change in the surrounding environment are different, the fracture and the degree of the decay are also different. Through analysis of rock mass in different stratums and comparison of lithology and fracture of the rock masses, the rock masses can be sub-divided into the rigid rock mass, loose rock mass and fractured rock mass based on the decision making objectives. As an information index reflecting the impact of lithology object on the safety of the travel route, geological structure is another key factor to be considered for the highway geology-based route selection in sensitive environmental condition in mountainous areas. Experiment results and experiences show that in places near large geological structures, factures are more vulnerable to highway geological disasters, which pose an impact on both causing a disaster chain with great destructive effects. Hence, the fault zone and other geological structure conditions pose a direct impact on the development and occurrence of highway geological disasters in sensitive environmental condition as well as on the safe operation of highways in mountainous areas. The geological structure 
object as a decision making object is very important for improving the reliability and safety of the route and avoiding various highway geological disasters. The specific procedures are as follows: The geological structure lines should be classified to establish different layers, and then these lines should be analyzed using the buffer area analyzing function and the space analyzing function of GIS to obtain the information about strong influencing zones, and comparing strong influencing zones and weak influencing zones. Following this, the significance of their impact on the travel route can be used as the information index that reflects the impact of geological structure object on the safety of travel route.

Environmental object: Rainfall is one of the factors to be considered for highway environmental-based route selection in sensitive environmental conditions of mountainous areas. It is a driving force for highway geological disaster and flood damage and is also the main source for triggering various factors that cause highway disasters in mountainous areas (water body). Therefore, rainfall is closely related to the development and occurrence of highway disasters. According to the analysis of the collected data, most of these disasters take place after a rainstorm or long-duration rains. Therefore, it is of great significance to take the rainfall factor as an object for highway route selection decision making model under complicated environmental conditions in mountainous areas. The rainfall intensity (the rainfall capacity within 10 minutes) is used for statistical analysis of space, and the information about strong influence zones for comparing strong influence zones and weak influence zones is obtained. The significance of their impact on travel route is used as information index reflecting the impact of rainfall object on the safety of travel routes. Vegetation is also one of the main factors to be considered for highway environmental-based route selection in crucial environmental conditions in mountainous areas. Hence, the use of vegetation as the object for building the highway route-selection decision making model in complicated environmental conditions of mountainous areas has great significance for carrying out highway projects and environmentally balanced development. Through space characteristics analysis of the environmental vegetation conditions, the area is divided into the zone with good vegetation, the zone with ordinary vegetation and the zone with weak vegetation. These zones are used as the information index reflecting the degree of impact of vegetation on the environmental protection of the travel route.

\section{DECISION MAKING MODEL FOR HIGHWAY DISASTER ROUTE SELECTION IN THE CRITICALENVIRONMENTAL CONDITION OF MOUNTAIN AREAS}

\subsection{Building of Single-object Function Model}

The above decision making indexes are then sub-divided into 3 layers using the space analyzing function of GIS, namely; the terrain object is divided into steep terrain, comparatively steep terrain and flat terrain. The rainfall

Table 1. Basic data of each project's object function.

\begin{tabular}{|c|c|c|c|c|c|c|c|c|}
\hline Object function & Weight & Index & Unit & \multicolumn{2}{|c|}{ Scheme I } & \multicolumn{2}{|c|}{ Scheme II } & Remarks \\
\hline Terrain object & 0.30 & $\begin{array}{c}\text { Flat } \\
\text { Comparatively steep } \\
\text { Steep }\end{array}$ & $\begin{array}{l}\mathrm{m} \\
\mathrm{m} \\
\mathrm{m}\end{array}$ & $\begin{array}{c}1,183 \\
956 \\
861\end{array}$ & 0.1073 & $\begin{array}{c}1,395 \\
872 \\
733\end{array}$ & 0.2207 & $\begin{array}{c}\text { The bigger the } \\
\text { better } \\
\text { The smaller the } \\
\text { better }\end{array}$ \\
\hline Geological object: lithology & 0.20 & $\begin{array}{c}\text { Stiff mass rock } \\
\text { Loose mass rock } \\
\text { Fractured mass rock }\end{array}$ & $\begin{array}{l}\mathrm{m} \\
\mathrm{m} \\
\mathrm{m}\end{array}$ & $\begin{array}{c}2,011 \\
592 \\
397\end{array}$ & 0.5380 & $\begin{array}{c}1,872 \\
388 \\
740\end{array}$ & 0.3773 & $\begin{array}{c}\text { The bigger the } \\
\text { better } \\
\text { The smaller the } \\
\text { better }\end{array}$ \\
\hline $\begin{array}{l}\text { Geological object: geological } \\
\text { structure }\end{array}$ & 0.15 & $\begin{array}{c}\text { Weak influence zone } \\
\text { Comparatively strong } \\
\text { influence zone } \\
\text { Strong influence zone }\end{array}$ & $\begin{array}{l}\mathrm{m} \\
\mathrm{m} \\
\mathrm{m}\end{array}$ & $\begin{array}{l}1,358 \\
805 \\
837\end{array}$ & 0.1737 & $\begin{array}{c}1,617 \\
621 \\
762\end{array}$ & 0.2850 & $\begin{array}{c}\text { The bigger the } \\
\text { better } \\
\text { The smaller the } \\
\text { better }\end{array}$ \\
\hline $\begin{array}{l}\text { Environmental object: } \\
\text { vegetation }\end{array}$ & 0.25 & $\begin{array}{l}\text { Good } \\
\text { Ordinary } \\
\text { Weak }\end{array}$ & $\begin{array}{l}\mathrm{m} \\
\mathrm{m} \\
\mathrm{m}\end{array}$ & $\begin{array}{c}1,539 \\
1,287 \\
174\end{array}$ & 0.4550 & $\begin{array}{c}1,384 \\
1,072 \\
544\end{array}$ & 0.2800 & $\begin{array}{c}\text { The bigger the } \\
\text { better } \\
\text { The smaller the } \\
\text { better }\end{array}$ \\
\hline
\end{tabular}


object is sub-divided into "heavy rain", "moderate rain" and "light rain"; the lithology is sub-divided into stiff rock mass, loose rock mass and fractured rock mass; the geological structure object is sub-divided into strong influence zones, the comparatively strong influence zone sand weak influence zones, and the vegetation object is sub-divided into good vegetation, ordinary vegetation and weak vegetation. After the classification, the space extracting function of GIS is used to extract the number of unit highway sections in different areas of the route schemes and denote them as $n_{1}, n_{2}$ and $n_{3}$. The following single-object function could be established as shown below:

$f_{i}(x)=\frac{n_{1}-n_{3}}{n_{1}+n_{2}+n_{3}}$

Where, $\mathrm{i}=1,2,3,4$, and 5 .

\subsection{Building of Multi-object Function Model}

According to the previously built single-object function model [17], a group of object functions for highway route selection in complicated environmental conditions in mountainous areas were studied and different calculation results of different single-object functions were used to generate the optimal route scheme. To allow single-object function to reach the optimal object, the object programming method was used in this study to build a multi-object function model as follows:

$\min \sum_{i=1}^{5} \omega_{i}\left|f_{i}(x)-f_{i}^{0}\right|$

Where, $w$ is the weight of a single object and following this, the AHP calculation method was used.

\section{APPLICATION EXAMPLE}

In this paper, a highway section with sensitive environmental condition was taken from a highway in the Three Gorges Reservoir Region as a sample and the design for the two schemes was made. The basic data of the decision making functions of each scheme are shown in Table 1. The single-object function value was calculated using Formula (1). Thus, the object-function optimal values of the two schemes were obtained as follows: $=0.2207$, $=0.5380,=0.2850,=0.3123$ and $=0.4550$. The multi-object function values were calculated using formula (2) and the multi-object function values of 0.0671 and 0.0759 were obtained for scheme I and scheme II respectively. Thus, it was observed that scheme I was better than Scheme II, as the calculation results of the model better correlated with the actual condition.

\section{CONCLUSION}

In this paper, the multi-object decision making theory was used to build a highway disaster route selection decision making model for sensitive environmental conditions in mountainous areas, which was formulized based on the qualitative and quantitative analysis of the terrain, geology of the environment and a number of other factors that may lead to highway disasters. The mathematical statistics theoretical method was used to classify and analyze various highway route selection decision making indexes, to extract the main representative indexes for building the decision making model. The model established was observed to have rigorous structure, high operability, as well as computability and realizability using computers.

\section{CONFLICT OF INTEREST}

The authors confirm that this article content has no conflict of interest.

\section{ACKNOWLEDGEMENTS}

This paper belongs to the project of the "National Natural Science Foundation of China ( NSFC )", No. 51378520; and "Chongqing municipal education commission fund projects", No. KJ110417.

\section{REFERENCES}

[1] D. You, and Y. Zhang, "Highway route selection decision making model for rolling terrain areas in plain," Highway Eng., vol. 34, no. 1, pp. 98-103, 2009.

[2] F. Zeng, "A study on relationship between geological structure and highway project construction," Highway Eng., vol. 35, no. 5, pp. 141-143, 2010.

[3] D. Ma, and C. Ai, "Idea of and experience in expressway route selection of complicated mountain areas," J. China Foreign Highway, vol. 35, no. 4, pp. 1-4, 2008.

[4] Q. Xu, L. Li, and Q. Tian, "Engineering geology-based route selection in sections with complicated terrain and geological conditions," J. China Foreign Highway, vol. 26, no. 4, pp. 11-13, 2006.

[5] Z. Wang, C. Yang, and P. Lu, "Comparison, selection and demonstration of highway route selection schemes in complicated mountain area environmental conditions - a case study based on ningxia-shaanxi connecting line of xihan expressway", J. China Foreign Highway, vol. 29, no. 4, pp. 276-279, 2009.

[6] B. Xia, N. Chang, and D. Nie, "A study on building of evaluation index system for eco-friendly highways", Highway Eng., vol. 37, no. 6, pp. 101-104, 2012.

[7] D. Peng, and S. Liu, "A discussion on prospective design and environmental protection for highways in mountain areas ", Human Commun Sci. Technol., vol. 36 no. 3, pp. 43-44, 2010.

[8] B. Ma, W. Tian, and T. Gao, "A study on pre-disaster identification method of highway geological disasters", Highways, no. 6, pp. 1-5, 2011.

[9] Y. Song, and J. Peng, "A discussion on geological disaster evaluation model for highways in mountain areas", J. Highway Transport. Res. Dev., vol. 22, no. 6, pp. 34-36, 2005.

[10] H. Chen, and H. Tang, "Geological disaster risk assessment of sichuan-tibet highway," Highways, no. 9, pp. 17-22, 2011.

[11] Y. Yang, W. He, and J. Lin, "Geological disaster risk assessment by sections for sangui expressway in Guizhou", Highways, no. 3, pp. 52-57, 2009.

[12] L. Ye, J. Xu, C. Zhuang, J. Yang, “A study on highway route optimization technology based on geological disaster risk assessment," Highways, no.9, pp. 12-16, 2011.

[13] T. Xu, F. Zhang, G. Zhang, R. Li, F. Yang, "Geological disaster risk assessment of yulin-tieshangang highway based on GIS," Journal of Guilin University of Technology, vol. 32, no.1, pp. 5562, 2012.

[14] X. Qiao, “A study on geological disaster risk assessment for areas along expressways in complicated mountain areas based on GIS," Xi'an: Chang'an University, 2006.

[15] Q. Sun, Y. Jia, and C Pan, "Highway route selection optimization in sections vulnerable to disasters in mountain areas based on 
multi-object decision makin," Journal of Wuhan University (the Engineering Ed.), vol. 44, no.5, pp. 633-637, 2011.

[16] L. Ye, C. Zhuang, "A Study on Intelligent Multi-object Decision Making Model for Highways", Roadbed Engineering, no. 4, pp.9091, 2009.
[17] J. Xu, and J. Li, "Theory and Method of Multi-object Decision Making", Tsinghua University Press, 2005

[18] C. Gao, "Theory and Method of Road Route Selection in Sections Vulnerable to Disasters in Mountain Areas," A Master's Thesis of Southwest Jiaotong University.

(C) Chuandong et al.; Licensee Bentham Open.

This is an open access article licensed under the terms of the Creative Commons Attribution Non-Commercial License (http://creativecommons.org/licenses/ by-nc/4.0/) which permits unrestricted, non-commercial use, distribution and reproduction in any medium, provided the work is properly cited. 